\title{
Atividade Física e Saúde no Nordeste Brasileiro
}

A área de atividade física e saúde tem ocupado lugar de destaque nos cenários nacional e internacional. Existem diferentes indicadores que podem ser utilizados para demonstrar o avanço e a consolidação da área: o Congresso Brasileiro de Atividade Física e Saúde, indo para a XI edição; os Simpósios Regionais em Atividade Física e Saúde, que serão realizados em todas as regiões do Brasil em 2014; o Congresso Internacional de Atividade Física e Saúde Pública, cuja última edição foi realizada esse ano no Rio de Janeiro; uma sociedade nacional, fundada em 2007 - Sociedade Brasileira de Atividade Física e Saúde (www.sbafs.org.br); e uma internacional - Sociedade Internacional de Atividade Física e Saúde (http://www.ispah.org), fundada em 2008; dois periódicos científicos: um nacional - Revista Brasileira de Atividade Física, periódico oficial da Sociedade Brasileira de Atividade Física e Saúde, e um internacional - Fournal of Physical Activity and Health, periódico oficial da Sociedade Internacional de Atividade Física e Saúde. Além disso, a presença de uma área de concentração e/ou linha de pesquisa em Atividade Física e Saúde em mais da metade dos Programas de Pós-graduação Stricto Sensu em Educação Física no Brasil, o crescente aumento da produção científica ${ }^{1,2,3,4}$, do número de grupos de pesquisa que investigam nessa área cadastrados no Diretório de Grupos de Pesquisa do Conselho Nacional de Desenvolvimento Científico e Tecnológico - CNPq, e, mais recentemente, a criação do curso Internacional de Formação em Atividade Física e Saúde Pública para professores doutores, similar ao Physical Activity and Public Health Course promovido pelo Centers for Disease Control and Prevention (CDC) nos Estados Unidos (http://www.sbafs. org.br/eventos), ratificam o importante crescimento da área.

A região Nordeste do Brasil, nos últimos 10 anos, tem contribuído de forma expressiva para o crescimento da área de Atividade Física e Saúde. Vários fatores têm sido importantes nesse cenário. Desde 1999, a região Nordeste tem realizado o Simpósio Nordestino de Atividade Física e Saúde. Esse evento tem sido um ponto de encontro para estudantes, profissionais e pesquisadores que militam na área de Atividade Física e Saúde debaterem sobre o tema. Em 2014, o XII Simpósio Nordestino de Atividade Física e Saúde será realizado em Maceió, AL (http://www.simposione2014.com). Houve um aumento expressivo no número de doutores na região (www.capes.gov.br), isso contribuiu para a criação e consolidação de diversos grupos de pesquisa e aumento das pesquisas e publicações na área de Atividade Física e Saúde ${ }^{2,3,4}$. É importante destacar que até o ano de 2008 não havia nenhum Programa de Pós-graduação em Educação Física no Nordeste. Desse modo, muitos professores tiveram que se deslocar até as regiões Sul e Sudeste do País para cursar o mestrado e doutorado em Educação Física. Vale a pena destacar o importante papel desempenhado pelo Programa de Pós-graduação em Educação Física da Universidade Federal de Santa Catarina na formação desses professores. Esse programa formou muitos pesquisadores que hoje desenvolvem suas atividades profissionais na região Nordeste, sobretudo na área de Atividade

Rev Bras Ativ Fis Saúde p. 271-274 $\mathrm{DOI}$

http://dx.doi.org/10.12820/rbafs.v.19n3p271

1 Universidade Federal da Paraíba UFPB. Grupo de Estudos e Pesquisas em Epidemiologia da Atividade Física e Saúde - GEPEAF. Programa Associado de Pósgraduação em Educação Física UPE/UFPB. 
Física e Saúde. Esses pesquisadores têm contribuído de maneira decisiva e estratégica para o aumento do número de grupos de pesquisa produtivos, das investigações e publicações na área de Atividade Física e Saúde. Isso também colaborou para o aumento da atração de doutores de outras regiões e áreas de concentração da Educação Física para o Nordeste.

Neste cenário, em 2008, foi criado o primeiro Programa de Pós-Graduação em Educação Física no Nordeste do Brasil, reunindo professores da Universidade de Pernambuco - UPE e da Universidade Federal da Paraíba - UFPB. No Programa Associado de Pós-Graduação UPE/UFPB (http:// w2.portais.atrio.scire.net.br/upe-papgef/), uma das áreas de concentração está voltada para Atividade Física e Saúde, bem como uma das linhas de pesquisa. $\mathrm{Na}$ sequência, outros dois programas de pós-graduação foram criados: em 2011, o Programa de Pós-graduação em Educação Física da Universidade Federal do Rio Grande do Norte - UFRN (http://www.sigaa.ufrn.br/sigaa/ public/programa/apresentacao.jsf?lc=pt_BR\&id=5591); em 2012, o Programa de Pós-graduação em Educação Física da Universidade Federal de Sergipe - UFS (https://www.sigaa.ufs.br/sigaa/public/programa/apresentacao. jsf?lc=pt_BR\&id=726). Em ambos os programas, há uma área de concentração e/ou linha de pesquisa em Atividade Física e Saúde. Em 2013, foi aprovado o primeiro curso de doutorado em Educação Física no Nordeste, do Programa Associado de Pós-graduação em Educação Física UPE/UFPB. É importante destacar que o curso de doutorado foi aberto antes mesmo do curso de mestrado completar cinco anos de existência.

Embora a criação dos Programas de Pós-graduação em Educação Física, particularmente do curso de doutorado, sejam fenômenos recentes na região Nordeste, e que representem apenas 11,1\% dos programas de pós-graduação e 9,5\% dos cursos de Pós-Graduação em Educação Física no Brasil (www. capes.gov.br), suas implicações para a produção científica, formação de pesquisadores e qualificação de recursos humanos já são observadas.

Uma busca à base corrente do Diretório de Grupos de Pesquisa do $\mathrm{CNPq}$ (http://dgp.cnpq.br/dgp/faces/consulta/consulta_parametrizada.jsf) identificou 89 grupos de pesquisa na área de Educação Física que tinham no seu nome, ou em uma das linhas de pesquisa, as palavras "atividade física e saúde”. Destes, cerca de $31 \%(n=27)$ eram da região Nordeste, perdendo apenas para a região Sul $(35 \% ; n=31)$. Isso demonstra quem em cinco anos o número de grupos de pesquisa em Atividade Física e Saúde na região Nordeste praticamente duplicou ${ }^{1}$. Isso pode ser atribuído à criação dos Programas de Pós-graduação em Educação Física e ao aumento do número de doutores na região (http:// estatico.cnpq.br/painelLattes/mapa/). Atualmente, a região Nordeste dispõe de 129 doutores em Educação Física, contra 465 e 271 nas regiões Sudeste e Sul, respectivamente (http://estatico.cnpq.br/painelLattes/mapa/).

Em relação à produção científica, publicações prévias têm destacado o crescente aumento do número de artigos publicados na área de Atividade Física e Saúde no Brasil ${ }^{1,2}$. As regiões Sul e Sudeste ainda concentram a maior proporção de publicações na área ${ }^{1,2,3,4}$. Entretanto, nos últimos anos, o número de artigos publicados por pesquisadores da região Nordeste cresceu de maneira expressiva. Em 2009, uma revisão sistemática demonstrou que apenas 11\% dos estudos em Epidemiologia da Atividade Física haviam sido realizados na região Nordeste, contra 36\% e $43 \%$ para as regiões Sul e Sudeste, respecti- 
vamente ${ }^{4}$. Revisões sistemáticas realizadas mais recentemente, abordando a mesma temática, demonstraram que a produção científica oriunda da região Nordeste representava de $20 \%$ a $25 \%$ das publicações identificadas, contra $26 \%$ e $46 \%$ para as regiões Sudeste e Sul, respectivamente ${ }^{2,3}$. Esse dado é relativamente animador, pois a região Nordeste tem um menor número de doutores e de Programas de Pós-graduação do que as regiões Sul e Sudeste, além do fato de que os programas de pós-graduação na região Nordeste ainda são recentes. Acredita-se que com a consolidação de seus programas existentes, com a criação de novos programas de pós-graduação e a formação de seus primeiros doutores, esse cenário será ainda mais promissor, marcado por um maior aumento na quantidade e qualidade das publicações na área. Criar redes de pesquisa entre os grupos de pesquisa, desenvolver projetos de pesquisa multicêntricos com universidades de outras regiões e do exterior são ações que precisam e devem ser realizadas na região Nordeste.

Apesar dos avanços conquistados nos últimos 10 anos na Educação Física e na área de Atividade Física e Saúde, em particular na região Nordeste do País, ainda há muitas dificuldades que precisam ser superadas. O cenário ainda é adverso quanto à democratização da formação de recursos humanos em nível de mestrado e doutorado em Educação Física em alguns estados como Alagoas, Bahia, Piauí, Maranhão e Ceará, que ainda não têm Programas de Pós-graduação em Educação Física. O baixo aporte de recursos financeiros para fomentar as pesquisas é outro problema a ser superado. Por exemplo: dos recursos aplicados do $\mathrm{CNPq}$ para a Educação Física, menos de $8 \%$ são para a região Nordeste $(7,9 \%)$. Esse valor é bem inferior ao que é destinado às regiões Sul (25,8\%) e Sudeste (48,3\%) do País. O somatório dos investimentos em pesquisa do CNPq no Norte, Nordeste e Centro-Oeste do país totaliza $25,8 \%$, ficando abaixo dos $30 \%$ estabelecidos pela política dessa agência de fomento. Outra ação necessária é fortalecer as agências estaduais de fomento, sobretudo aquelas em que o fomento à pesquisa tem sido praticamente inexistente, por exemplo a FAPESQ, no Estado da Paraíba. Também é necessário que o $\mathrm{CNPq}$ ajuste sua política de fomento à pesquisa, não só aumentando o aporte de recursos destinados à região Nordeste, dado o aumento no número de doutores e de programas de pós na região, mas, sobretudo, aplicando na sua plenitude a fração dos recursos destinados ao Nordeste, conforme estabelecido na sua política. Isso contribuirá para quebrar o ciclo vicioso: menor aporte de recursos, menor número de projetos de pesquisa financiados, menor número de publicações científicas, menor capacidade de concorrer de forma efetiva aos editais de financiamento devido a baixa produtividade, menor número de publicações. Esse ciclo vicioso tem influenciado negativamente a atração e fixação de doutores produtivos na região.

É preciso aumentar o número de Programas de Pós-graduação em Educação Física na região. A criação de programas associados entre instituições que não dispõem de um número mínimo de professores com titulação e publicação necessário deve ser mais uma meta da região para os próximos anos. Além disso, é preciso consolidar os programas de pós-graduação existentes e ampliar o número de cursos de doutorado em Educação Física. A realização do X Congresso Brasileiro de Atividade Física e Saúde, na cidade de São Luiz, fora do circuito dos principais grupos de pesquisa na área, sob a Presidência do Prof. Dr. Wellington Roberto Carvalho e sua equipe na Uni- 
versidade Federal do Maranhão, promoverá uma grande revolução na região. Este pode ser um importante momento para se refletir sobre as possibilidades de criação de Programas de Pós-graduação em Educação Física no Nordeste e estimular a vinda de doutores de outras regiões do País.

A região Nordeste mostra-se muito promissora para se tornar um dos maiores centros de formação de pesquisadores e produção científica em Educação Física, com foco na área de Atividade Física e Saúde, no Brasil. Dado o cenário atual e olhando para o futuro, é possível que essa previsão seja concretizada em breve. Essa jornada exigirá uma política agressiva de recursos humanos, no sentido de atrair e fixar doutores produtivos na área de Atividade Física e Saúde, de outras regiões do Brasil, em associação à formação qualificada de doutores da própria região, ao aumento do aporte de recursos destinados ao fomento das pesquisas e produção científica qualificada na área, e à ampliação do número de programas de pós-graduação, sobretudo com doutorado.

\section{REFERÊNCIAS}

1. Nahas MV, Garcia LMT. Um pouco de história, desenvolvimentos recentes e perspectivas para a pesquisa em atividade física e saúde no Brasil. Rev Bras Educ Fís Esporte 2010; 24(1): 135-48.

2. Dumith, SC. Physical activity in Brazil: a systematic review. Cad Saude Public 2009; 25(Sup 3): S415-S426.

3. Barbosa Filho VC, Campos W, Lopes AS. Epidemiology of physical inactivity, sedentary behaviors, and unhealthy eating habits among Brazilian adolescents: a systematic review. Cien Saude Col 2014, 19(1):173-193.

4. Hallal PC, Dumith SC, Bastos JL, Reichert FF, Siqueira FV, Azevedo MR. Evolução da pesquisa epidemiológica em atividade física no Brasil: revisão sistemática. Rev Saúde Pública 2007;41(3):453-60. 